\title{
MENGINTERKONEKSI SAINS DAN AGAMA DALAM PEMBELAJARAN IPA DI SEKOLAH DASAR
}

\author{
Yuliana Susanti \\ STIT Palapa Nusantara Lombok NTB \\ yuliana.susanti27@gmail.com
}

\begin{abstract}
The development of science is interwoven with ideology. Therefore, a fundamental problem that always arises: is Islam complementary with natural science in harmony, or is there an unresolved complication between the metaphysical system based on religion and the demands of reason with empirical research? For a thousand years philosophers and Islamic theologians have considered this problem, which constantly invites intense and disagreeable debate. The word science comes from the Latin "scientia" which means knowledge. According to Webster New Collegiate Dictionart, the definition of science is "knowledge acquired through learning and proof" or "knowledge that covers a general truth of the natural laws that occur. Whereas according to Ibn Kaldun in Miqowin, science is a history of science developed almost entirely based on reason and empirical world experience.
\end{abstract}

Keywords: Islam, Science, Learning

\begin{abstract}
Abstrak : Perkembangan sains terjalin berkelindan dengan ideologi. Oleh Sebab itu, masalah mendasar yang senantiasa timbul: apakah agama islam saling melengkapi dengan ilmu pengetahuan alam secara harmonis, atau dijumpai konflik yang tidak terselesaikan antara sistem metafisika yang didasarkan atas agama dan tuntutan akal dengan penelitian empiris? Selama seribu tahun para filosofis dan teolog islam telah mempertimbangkan masalah ini, yang terus-menerus mengundang debat yang intens dan ketaksepakatan. Kata sains berasal dari bahasa latin "scientia" yang berarti pengetahuan. Menurut Webster New Collegiate Dictionart, definisi dari sains adalah "pengetahuan yang diperoleh melalui pembelajaran dan pembuktian "atau" pengetahuan yang melingkupi suatu kebenaran umum dari hukum-hukum alam yang terjadi. Sedangkan menurut Ibnu Kaldun dalam Miqowin, sains adalah sejarah ilmu yang dikembangkan hampir sepenuhnya berdasarkan akal dan pengalaman dunia empiris.
\end{abstract}

Kata Kunci: Islam, Sains, Pembelajaran

Volume 1, Nomor 2, Juli 2019; 89-101

https:// ejournal.stitpn.ac.id/index.php/islamika 


\section{PENDAHULUAN}

Sekitar 700 tahun yang lalu, peradaban islam hampir kehilangan sama sekali semangat dan kemampuan untuk melakukan pencapaian dalam sains. Sejak saat itu, terlepas dari upaya-upaya selama era Utsmani dan Mesir Zaman Muhammad Ali, tidak dijumpai upaya-upaya yang berarti untuk memulihkan diri kembali. Tidak pelak, ini menjadi kesibukan utama kalangan modernis dalam islam.

Tetapi sebagian besar kaum tradisionalis tidak merasa menyesali banyak di antara mereka menyambut tanpa rasa prihatin kenyataan ini; sebab, dalam pandangan mereka menjaga jarak terhadap sains berarti ikut membantu melindungi islam dari pengaruh-pengaruh duniawi yang merusak. Melihat dari beberapa permasalahan ini, maka sebagai seorang ilmuan seharusnya mempunyai cara untuk menyatukan itu semua, dengan tujuan agar semua ilmu itu tidak saling menyerang antara satu dengan yang lain.

\section{Agama dan Sains}

Kita mendengar kata "sains" dan "agama", serta-merta kita berpikir akan sejarah hubungan antara di antara keduanya. Pertemuan agama dengan sains tidak hanya berupa pertentangan belaka. ${ }^{1}$ Sehingga timbul dari pemikir memberikan solusinya, yaitu dari Ian G. Barbour danJhon F.Haught. Masing-masing pemikir ini mempunyai cara dan tawaran.

Ian G.Barbour menawarkan 4 pandangan tentang hubungan sains dan agama, diantaranya: Pertama, Konflik. Pandangan konflik mengemuka pada abad ke-19, beberapa sejarawan mutakhir menunjukkan bahwa bukti yang mereka sodorkan sangat selektif dan pandangan-pandangan alternatif tentang hubungan sains dengan agama telah dianut secara luas selama berabad-abad.

Kedua, Independensi. Agar tidak terjadi konflik antara agama dan sains maka kedua bidang ini harus di pisahkan pada kawasan yang berbeda. Ketiga, Dialog memotret hubungan yang lebih konstruktif antara sains dan agama daripada pandangan konflik dan independensi. Keempat, Integrasi. Beberapa penulis menyerukan perumusan ulang gagasan teologi tradisional yang lebih ekstensif dan

1Jhon F. Haufht, Perjumpaan Sains Dan Agama, Judul Asli Science And Religion: From Confluct To Conversation, Diterjemah Oleh Fransiskus Borgias (Bandung: Mizan, 2004), Hlm.,1. 
sistematis daripada yang dilakukan oleh pendukung dialog. Ada tiga versi berada dalam integrasi. Dalam natural theology, terdapat klaim bahwa ekstensi tuhan dapat disimpulkan dari (atau didukung oleh) bukti tentang desain alam, yang tantangannya alam membuat kita semakin menyadarinya. ${ }^{2}$

Haugh. Dia memberikan empat solusi juga, yaitu: Pertama. Pendekatan konflik: pendekatan ini berpendapat bahwa antara sains dan agama tidak mungkin untuk dapat di satukan. Kedua, Pendekatan kontres: menurut pendekatan ini bahwa antara sains dan agama tidak mempunyai perselisihan sebab keduanya mempunyai tanggapan tersendiri mengenai setiap permasalahan. Ketiga, Pendekatan kontak: suatu upaya untuk mendamaikan antara sains dan agama dengan cara dialog. Keempat, Pendekatan konfirmasi: suatu perspektif yang menyoroti cara-cara agama, pada tataran yang mendalam, mendukung dan menghidupkan segala kegiatan ilmiah. Dari beberapa penawaran di atas, perlu kita klarifikasi yang cocok untuk pembelajaran khususnya di dunia pendidikan. ${ }^{3}$

Pendekatan dalam membicarakan hubungan islam, sains dan teknologi yaitu : (1) Menunjukkan bagaimana islam mendorong, membangkitkan, merangsang, dan mengalami penemu sains dan teknologi. (2) Mengulas sumbangan umat islam bagi perkembangan sains dan teknologi. (3) Membahas secara falsafi islam, sains dan teknologi. (4) Menentukan apakah ada islam yang islami. (5) Menggambarkan bagaimana perkembangan sains dan teknologi dewasa ini, lalu apa yang harus dilakukan? ${ }^{4}$ Pendekatan itu perlu untuk melirik hal yang di atas, dengan tujuan untuk lebih melihat cara dan alat dalam hal melakukan pendekatan atau pertemuan dalam islam dan sains tersebut.

\section{Kerangka Dasar Integrasi-Interkoneksi Ilmu}

Pada dasarnya, islam sebenarnya tidak melakukan dikotomi antara ilmu-ilmu qauliyyah/hadlarah al-nash (ilmu-ilmu yang berkaitan dengan teks keagamaan) dengan ilmu kauniyyah-ijtima'iyyah/hadlarah al-falsafah (ilmu-ilmu etis filosofis), ilmu yang di sebutkan diatas termasuk ilmu-ilmu keislaman bila dilihat secara epistimologis yang

${ }^{2}$ Ian G. Barbour, Juru Bicara Tuhan, Judul Asli When Science Meets Religion: Enemies, Stranges, Or Partuners ?, Alih Bahasa E.R. Muhammad (Bandung: Mizan, 2002), Hlm.,47-83.

${ }^{3}$ Amin Abdullah...hlm.,18.

${ }^{4}$ Jalaluddin Rahmat, Islam Alternative, (Bandung: Mizan, 1998). Hlm.148 
mulai dari nilai-nilai dan etika islam. Ilmu Islam pada dasarnya mulai dari nilai-nilai yang bersifat objektif.

Seluruh keilmuan diatas dapat dikembangkan dengan melalui konsep badlarah al-nash, hadlarah al-ilm, maupun hadlarah al-falsafah. Wilayah keilmuan tersebut tidak dikaji secara parsial melainkan dikaji secara integratif-interkonektif atau saling berhubungan satu dengan lainnya. Secara jelasnya, paradigma keilmuan tersebut bisa digambarkan seperti “jarring laba-laba keilmuan” yang sering kita lihat di UIN Sunan Kalijaga.

Jadi yang dimaksud dengan pendekatan integratif di sini adalah perpaduan kebenaran wahyu (burban ilabi) dalam bentuk pembidangan mata pelajaran yang terkait dengan nash(hadlarah al-nash), dengan bukti-bukti yang ditemukan di alam semesta ini (burhan kaum) dalam bentuk pembidangan mata pelajaran (sekolah)empiris-kemasyarakatan dan kealaman (hadlarah al-ílm), dan pembidangan mata pelajaran (sekolah) tersebut dengan falsafah dan etika (hadlarah al-falsafah).

Dikatakan struktur keilmuan integratif di sini bukanlah bahwa antar berbagai ilmu mengalami peleburan menjadi satu bentuk ilmu yang identik, melainkan terpadunya karakter, corak, dan hakikat antar ilmu tersebut dalam semua kesatuan dimensinya. Adapun pendekatan interkonektif adalah sebuah pendekatan yang saling keterkaitan antara bidang ilmu yang satu dengan ilmu yang lain dan saling menghargai.

\section{Ranah Integrasi-Interkoneksi Ilmu}

Pertama, Ranah filosofis. Pada ranah filosofis ini dimaksudkan bagaimana setiap pengetahuan harus memiliki nilai yang fundafental eksitensial dengan ilmuilmu yang lain dan mempunyai nilai yang humanis di dalam pembelajaran. Mengajarkan fiqih misalnya di samping makna fundamentalnya sebagai filosofis membangun hubungan antar manusia, alam dan tuhan dalam ajaran islam, dalam pengajaran fiqih harus juga ditanamkan pada peserta didik bahwa eksistensi fiqih tidaklah berdiri sendiri atau bersifat self-sufficeint, melainkan berkembang bersama disiplin keilmuan lain. 
Kedua, Ranah materi. Maksudnya di mana dalam pembelajaran harus di hubungkan atau di integrasi interkoneksi antara pembelajaran umum dengan pembelajaran keislaman. Seperti mata pelajaran umum seperti antropologi, sosiologi, dll. Sebaliknya ilmu-ilmu umum ke dalam kajian-kajian keagamaan dan keislaman.

Ranah materi mempunyai tiga model dalam mengimplementasi integrasi interkoneksi, tiga model tersebut yakni:(1) model pengintegrasian ke dalam paket kurikulum. (2) model penanaman mata kuliah yang menunjukkan hubungan antar dua disiplin ilmu umum dan keislaman.(3) model pengintegrasian ke dalam tematema mata kuliah.

Ketiga, Ranah Metodologi maksudnya yaitu metodologi yang digunakan dalam pengembangan ilmu yang bersangkutan. Setiap ilmu memiliki metodologi penelitian yang khas yang biasa digunakan dalam pengembangan kurikulum. Sebagai contoh, psikologi memiliki metode yang khas seperti introsepsi, ekstrospeksi dan retrospeksi di samping metode-metode lain yang sifatnya umum seperti kuesioner, wawancara, observasi dan lain-lain. Metode di sini juga bisa dalam pengertian yang lebih luas yang berupa pendekatan (approach). Sebagai contoh dalam psikologi sekarang dikenal dengan pendekatan-pendekatan fenomenologis, kontemplatif bahkan normatif.

Jadi intinya dari ketiga di atas yang dapat kita lakukan dalam pembelajaran adalah model yang kedua, karena model yang kedua lebih mengarah kepada proses pembelajaran di kelas khususnya di dunia pendidikan baik di SD, SMP dan SMA. ${ }^{5}$

\section{Langkah-langkah mengapresiasikan Agama dan sains dalam pembelajaran}

Sebelum kita melangkah lebih jauh tentang cara mengapresiasikan islam dan sains dalam pembelajaran, alangkah baiknya kita tahu dulu apa sains itu sebenarnya dan seperti apa hakikat sains itu.

\section{Pengertian Sains}

Ilmu pengetahuan (sains)", agar pohon bisa tumbuh dan berkembang tentu memerlukan akar yang kuat, akar sains yang kuat itu adalah "agama. Kata sains berasal dari bahasa latin "scientia" yang berarti pengetahuan. Menurut Webster New Collegiate Dictionart, definisi dari sains adalah "pengetahuan yang diperoleh melalui

${ }^{5}$ Amin Abdullah, dkk,..31 
pembelajaran dan pembuktian "atau" pengetahuan yang melingkupi suatu kebenaran umum dari hukum-hukum alam yang terjadi. ${ }^{6}$ Sedangkan menurut Ibnu Kaldun dalam Miqowin, sains adalah sejarah ilmu yang dikembangkan hampir sepenuhnya berdasarkan akal dan pengalaman dunia empiris. ${ }^{7}$

Jadi dari pengertian di atas dapat ditarik kesimpulan, bahwa sains adalah pengetahuan yang didapatkan melalui suatu proses baik itu yang bersifat pembelajaran, diskusi, membaca kemudian dibuktikan dengan bukti-bukti yang nyata atau pakta.

\section{Hakikat}

Untuk membahas hakikat sains, diperlukan sebuah kajian kritis. Ini tentu saja akan membawa konsekuensi pada cara pandang orang dalam menanggapi dan menghayati sains. Akibat cara pandang orang (guru) mengenai apa itu sains, dalam lingkungan yang sempit, akan membawa warna pada pembelajaran yang diterapkan manakala guru melakukan aktivitas bersama anak dalam pembelajaran sains. Untuk membahas hakikat sains, ada beberapa hal yang perlu diperhatikan, menurut Hardy dan Fleer (1996:15-16), sehingga memungkinkan para guru untuk memahami pengertian sains dalam perspektif yang lebih luas.

\section{Sains sebagai kumpulan pengetahuan}

Sains sebagai kumpulan pengetahuan mengacu pada kumpulan berbagai konsep sains yang sangat luas. Sains dipertimbangkan sebagai akumulasi berbagai pengetahuan yang telah ditemukan sejak zaman dahulu sampai penemu pengetahuan yang sangat baru. Pengetahuan tersebut berupa pakta, konsep, teori, dan generalisasi yang menjelaskan tentang alam.

\section{Sains sebagai suatu proses penelusuran (investigation)}

Sains sebagai proses penelusuran umumnya merupakan suatu pandangan yang menghubungkan gambaran sains yang berhubungan erat dengan kegiatan laboratorium beserta perangkatnya. 


\section{Sains sebagai kumpulan nilai}

Sains sebagai kumpulan nilai berhubungan erat dengan penekanan sains sebagai proses. Bagaimana juga, pandangan ini menekankan pada aspek nilai ilmiah yang melekat dalam sains. Ini termasuk didalamnya nilai kejujuran, rasa ingin tahu, dan keterbukaan akan berbagai fenomena yang baru sekalipun.

\section{Sains sebagai cara untuk mengenal dunia}

Proses sains dipengaruhi oleh cara di mana orang memahami kehidupan dan dunia di sekitarnya. Sains dipertimbangkan sebagai suatu cara diaman manusia mengerti dan memberi makna pada dunia di sekeliling mereka.

\section{Sains sebagai institusi sosial}

Ini berarti bahwa sains seharusnya dipandang dalam pengertian sebagai kumpulan para profesional, di mana melalui sains para ilmuan dilatih dan diberi penghargaan akan hasil karya yang telah dihasilkan, didanai, dan diatur dalam masyarakat, dikaitkan dengan unsur pemerintah, bahkan dipengaruhi oleh politik. Salah satu kenyataan adalah saat ini baik ilmuan mengembangkan sains untuk keperluan pertahanan militer.

\section{Sains sebagai hasil konstruksi manusia}

Pandangan ini menunjuk pada pengertian bahwa sains sebenarnya merupakan penemuan dari suatu kebenaran ilmiah mengenai hakikat semesta alam. Pengetahuan ilmiah ini tidak lain merupakan akumulasi kebenaran. Hal pokok dalam pandangan ini adalah sains merupakan konstruksi pemikiran manusia. Oleh karenanya, dapat saja apa yang dihasilkan sains memiliki sifat bias dan semesta. ${ }^{8}$

\section{Langkah-langkah pembelajaran sains dalam pembelajaran}

Ilmu pengetahuan alam (IPA) atau sains (dalam arti sempit) sebagai disiplin ilmu terdiri atas physicalscience dan lifescience. Termasuk physicalscience adalah ilmu-ilmu

${ }^{8}$ Sumaji, Dkk. Pendidikan Sains Yang Humanis (Yogyakarta: Kanisius, 1998), Hlm.,113-115. 
Astronomi, Kimia, Geologi, Mineralogy, Matearologi, dan Fisika: sedangkan lifescience meliputi Biologi, Zoology, dan Fisiologi.

Pendidikan IPA di Indonesia dititikberatkan pada upaya penyiapan kaderkader pembangunan IPTEK yang tangguh untuk masa yang akan datang (era PJPT II), dengan memperhatikan nilai-nilai sosial, budaya, etika, moral, dan agama.

Dengan demikian, penilaian pendidikan IPA mencakup ruang lingkup yang luas pula. Oleh karena itu, konteks pembahasan di sini hanya dibatasi pada pendidikan formal. Bila kita meninjau konteks pendidikan formal sebagai suatu sistem, kaitannya dengan unsur-unsur lain dapat digambarkan dengan bantuan diagram berikut:

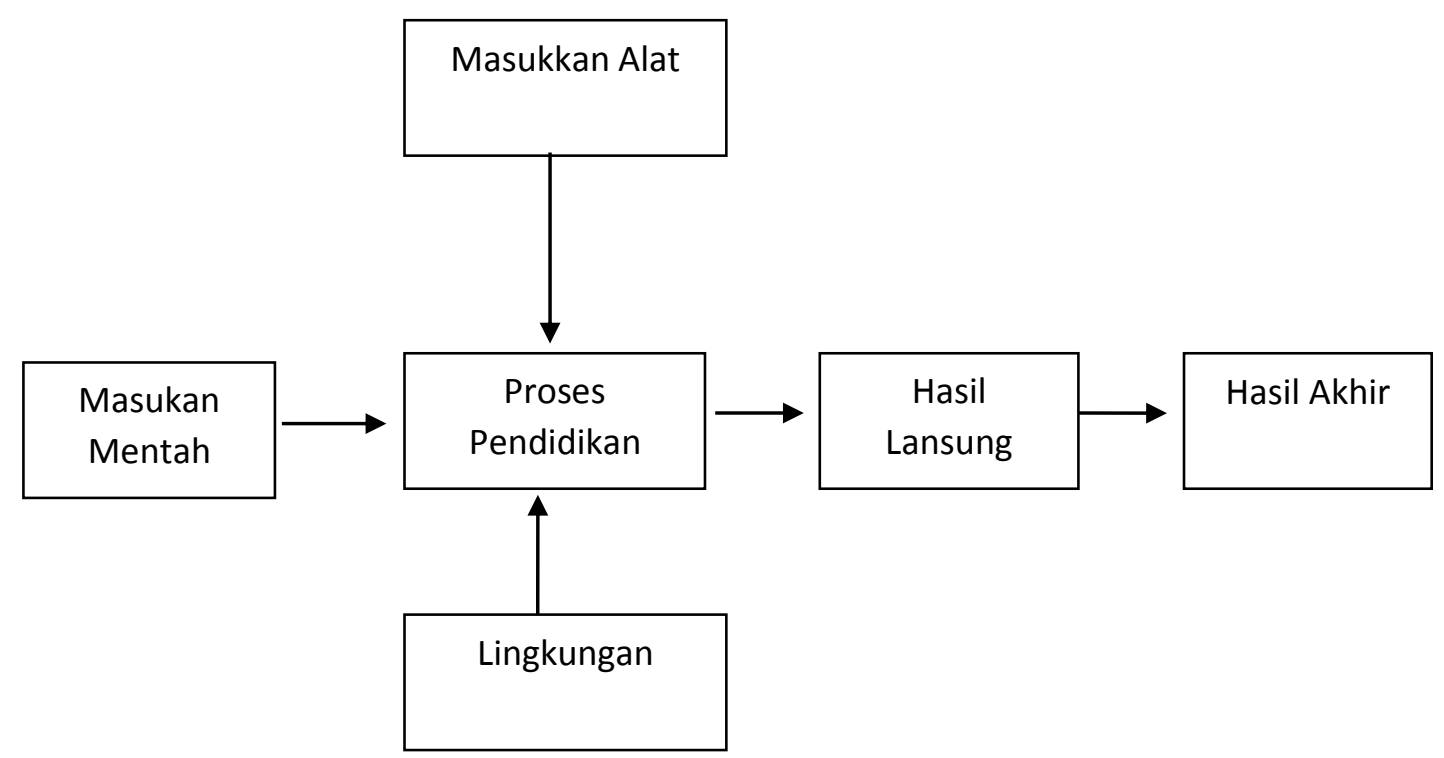

Adapun maksud dari bagan tersebut yaitu : a) Masukan mentah terdiri atas siswa dalam sistem pendidikan di sekolah. b). Masuk alat terdiri atas unsur-unsur seperti: tujuan pendidikan, kerangka, tujuan, materi kurikulum, fasilitas, media pendidikan, sistem administrasi, sistem penyimpanan, tenaga pengajar, sistem evaluasi, bimbingan dan penyuluhan. c). Lingkungan terdiri atas lingkungan ekologi dan masyarakat (termasuk lingkungan masyarakat) yang dapat mempengaruhi proses pendidikan. d). Proses pendidikan merupakan proses interaksi antarunsur masukan mentah untuk mencapai tujuan pendidikan. e). Hasil langsung pendidikan adalah prilaku (Behaviour) anak didik (masukan mentah) setelah mereka mengalami proses pendidikan. f). Hasil akhir pendidikan adalah prilaku anak didik setelah mereka terjun 
dalam kehidupan masyarakat luas (termasuk melanjutkan sekolah) sebagai hasil proses pendidikan. ${ }^{9}$

Merujuk dari pemaparan di atas, maka dapat dibuat proses pembelajaran sebagai berikut: a) Siswa memberikan masukan kepada sekolah atau guru terkait dengan mata pelajaran, dengan tujuan agar dalam pembelajaran lebih baik dan menyenangkan. b) Dalam pembelajaran guru diharuskan untuk menggunakan alat atau media pembelajaran, agar minat belajar siswa menjadi terpancing dan tidak cepat bosan. c) Dalam pembelajaran seorang guru harus bisa memanfaatkan lingkungan sebagai media, karena media yang paling baik adalah yang ada di sekitar kita bukan media yang canggih. Karena kita ketahui bahwa tidak semua sekolah lengkap dengan media, dengan melihat realitas seperti itu maka guru diminta untuk kreatif dengan memanfaatkan lingkungan di sekitar sebagai media pembelajaran. d) Dengan memanfaatkan lingkungan maka siswa bisa mengamati secara langsung dan terjun langsung ke dalam pembelajaran sehingga hasil dari pembelajarannya itu bisa memuaskan. Adapun bentuk RPP dalam pembelajaran sains yaitu :

\section{Rencana Pelaksanaan Pembelajaran}

(RPP)

$\begin{array}{ll}\text { Nama sekolah } & : \text { MI Muhammadiah 1 Sapen } \\ \text { Mata pelajaran } & : \text { Ilmu Pengetahuan Alam (IPA) } \\ \text { Kelas/semester } & : 2 \\ \text { Alokasi waktu } & : 2 \times 40 \text { Menit. }\end{array}$

Standar kompetensi $\quad$ 1. Memahami matahari sebagai pusat tata surya dan interaksi bumi dan tata surya.

Kompetensi dasar : 1. Menjelaskan terjadinya gerhana bulan dan gerhana matahari.

Indikator

: 1. Mendemonstrasikan terjadinya gerhana matahari.

2. Menjelaskan penyebab terjadinya gerhana matahari.

3. Menggambarkan sketsa peristiwa gerhana matahari.

${ }^{9}$ Sumaji, PendidikanSainsYangHumanis(Yogyakarta: Kanisius, Cet ke-6 2009), hlm.,31-40 
Tujuan Pembelajaran:

Setelah mempelajari materi ini, siswa diharapkan mampu:

1. Mendemonstrasikan terjadinya gerhana matahari melalui peragaan sederhana dengan jelas.

2. Menjelaskan posisi matahari, bulan, dan bumi saat gerhana matahari melalui peragaan dengan benar.

3. Menyimpulkan penyebab gerhana matahari berdasarkan pengamatan saat peragaan dengan benar.

4. Menjelaskan terjadinya gerhana matahari total, sebagian, dan cincin berdasarkan peragaan dengan benar.

5. Menggambarkan sketsa pristiwa gerhana matahari pada kertas gambar dengan baik dan benar.

Metode pembelajaran

1. Ceramah

2. Tanya jawab

3. Demonstrasi

4. Diskusi

Langkah-langkah kegiatan pembelajaran

1. Pendahuluan

a. Guru mengajak siswa untuk mengingat kembali pelajaran sebelumnya tentang rotasi dan revolusi bumi, serta rotasi dan revolusi bulan.

b. Guru bertanya kepada siswa, "apakah kalian pernah mendengar kata gerhana"?

c. Guru mengimformasikan bahwa pemelajaran hari ini adalah gerhana bulan.

d. Guru mengajukan pertanyan lagi kepada para siswa, "bagaimana terjadinya gerhana matahari ?’.

2. Kegiatan inti.

a. Guru menyajikan gambaran sekilas tentang gerhana dan gerhana matahari. 
b. Guru bersama siswa menyiapkan alat/bahan yang diperlukan untuk demonstrasi gerhana matahari, yaitu bola besar (model bumi) dan bola kecil (model bulan).

c. Guru meminta kepada seorang siswa untuk memegang bola kecil, sedangkan siswa lainya mengarahkan senter ke bola tersebut.

d. Guru mengatur kedudukan senter dan bola kecil, sehingga dapat membentuk baying-bayang pada dinding kelas.

e. Guru meminta kepada siswa lainya untuk mengamati baying-bayang pada dinding kelas.

f. Guru meminta kepada seornag siswa lagi utnuk mengarahkan bola besar (model bumi) secara perlahan masuk ke dalam baying-bayang bola kecil (model bulan).

g. Guru mengajukan pertanyaan kepada siswa, "apa yang kamu amati pada permukaan bola besar dalam peragaan yang dilakukan ?"

3. Penutup.

a. Melakukan penilaian demonstrasi yang dilakukan pada hari itu.

b. Sebagai kesimpulan, guru menunjuk beberapa siswa utnuk menyatakan kesimpulan pelajaran oada hari itu.

c. Pemberian tugas.

Sumber, alat, dan media pembelajaran

1. Sumber:

Buku IPA kelas VI SD, pusat pembuuan departemen pendidikan nasional.

2. Alat:

Bola kecil dan besar.

3. Media pembelajaran:

Gambar gerhana matahari.

Penilaian

1. Tes tertulis

a. Tugas

Membuat gambar posisi matahari, bumi, dan bulan saat terjadi gerhana matahari, disertai dengan penjelasan proses terjadinya pada kertas gambar. 
b. Asperk-aspek yang dinilai adalah:

1) Ketepatan gambar.

2) Ketepatan penjelasan proses gerhana matahari.

3) Estetika gambar (bentuk, warna, kerapian dan kebersihan).

2. Keaktifan selama proses pembelajaran. ${ }^{10}$

\section{KESIMPULAN}

Dari pembahasan di atas dapat kita simpulkan, diantaranya : dalam dunia yang sudah serba maju seperti sekarang ini kita tidak boleh saling mengklaim antara agama yang satu dengan yang lain, atau saling mengunggulkan antara pakultas yang satu dengan yang lain. Ketika di suatu perguruan tinggi melihat hal seperti itu, maka tugas kita adalah bagaimana caranya supaya tidak saling menjauhi tapi bagaimana caranya supaya saling menyapa. Dalam pembelajaran kita perlu menyisipkan nilai-nilai keislaman dalam pembelajaran tidak hanya di sains saja tapi di semua disiplin ilmu.

Ian G. Barbour menawarkan 4 pandangan tentang hubungan sains dan agama, diantaranya : Pertama, Konflik. Pandangan konflik mengemuka pada abad ke-19, beberapa sejarawan mutakhir menunjukkan bahwa bukti yang mereka sodorkan sangat selektif dan pandangan-pandangan alternatif tentang hubungan sains dengan agama telah dianut secara luas selama berabad - abad. Kini, potret populer "perang sains melawan agama" dipertajam oleh media karena kontroversi antara materialisme ilmiah dan literalisme ilmiah biblical jauh lebih diminati khalayak daripada posisi moderat.

\section{DAFTAR PUSTAKA}

Amin Abdulah, Dkk. Kerangka Dasar Keilmuan \& Pengembangan Kurikulum UIN Sunan Kalijaga Yogyakarta, Yogyakarta: Pokja Akademik, 2006.

Amin Abdullah, Menyatukan Kembali Ilmu-Imu Agama Dan Umum, Yogyakarta: SukaPress, 2003.

Http;//Www. Sciemadesimple.Com/Sciene,Definition, Html. Selasa, 14;07

Ian G. Barbour, Juru Bicara Tuhan, Judul Asli When Science Meets Religion: Enemies, Stranges, Or Partuners ?, Alih Bahasa E.R. Muhammad, Bandung: Mizan, 2002.

${ }^{10}$ Sitiatava Rizema Putra, Desain Belajar Mangajar Kreatif Berbasis Sains (Jogjakarta: Diva Press, 2013). Hlm.114-121. 
Jhon F. Haufht, Perjumpaan Sains Dan Agama, Judul Asli Science And Religion: From Confluct To Conversation, Diterjemah Oleh Fransiskus Borgias, Bandung: Mizan, 2004.

MaksudinParadigma Agama Dan Sains Nondikotomi, Pustaka Pelajar,2003.

Pervez Hoodbhoy, Islam Dan Sains, Judul Asli Islam And Science Religions Orthodoxy And The Battle For Rationality, Diterjemah Oleh Luqman, Bandung: Pustaka, 1997.

Sitiatava Rizema Putra, Desain Belajar Mangajar Kreatif Berbasis Sains, Jogjakarta: Diva Press, 2013.

Sumaji, Dkk. Pendidikan Sains Yang Humanis, Yogyakarta: Kanisius, 1998.

Sumaji, PendidikanSainsYangHumanis, Yogyakarta: Kanisius, Cet ke-6 2009. 